\title{
Hubungan Antara Lokasi Sekolah terhadap Metode Mengajar Guru dan Hasil Ujian Nasional Geografi
}

\author{
Arvina Meyzilia ${ }^{*}{ }^{*}$, Darsiharjo ${ }^{2}$, Mamat Ruhimat ${ }^{3}$ \\ 1 Jurusan Pendidikan Geografi, Universitas Pendidikan Indonesia, Bandung, Indonesia \\ ${ }^{2} J u r u s a n$ Pendidikan Geografi, Universitas Pendidikan Indonesia, Bandung, Indonesia \\ ${ }^{3}$ Jurusan Pendidikan Geografi, Universitas Pendidikan Indonesia, Bandung, Indonesia
}

\section{A R T I C L E I N F O}

\section{Article history:}

Received 29 April 2018

Accepted 28 Juni 2018

Available online 30 Juni 2018

\section{Kata Kunci:}

Geografi; Lokasi Sekolah

Metode Mengajar Guru

Keywords:

Geography; School Location;

Teacher Teaching Method

\begin{abstract}
A B S T R A K
Lokasi sekolah mempengaruhi hasil belajar siswa. Sekolah yang terletak di desa dan di kota memiliki hasil belajar yang berbeda. Sekolah yang terletak di kota memiliki hasil belajar yang lebih baik daripada sekolah yang terletak di desa. Selain itu, terdapat perbedaan efektifitas mengajar guru di desa dan di kota sehingga mempengaruhi hasil belajar siswa. Salah satu pengukuran hasil belajar yang dilakukan pemerintah Indonesia adalah dengan Ujian Nasional (UN). Geografi merupakan salah satu mata pelajaran peminatan yang diikut sertakan dalam UN. Berdasarkan penilaian Puspendik, hasil UN Geografi di Kabupaten Bangka tahun 2017 tergolong dalam kategori sedang. Penelitian ini merupakan penelitian kuantitatif deskritif. Sampel penelitian yaitu seluruh SMA Negeri di Kabupaten Bangka. Alat yang digunakan untuk mengumpulkan data berupa angket. Hasil penelitian menunjukkan (1) Ada hubungan positif antara lokasi sekolah terhadap hasil UN geografi siswa SMA Negeri Se-Kabupaten Bangka Tahun 2017, (2) Tidak ada hubungan positif antara lokasi sekolah terhadap metode mengajar guru geografi SMA Negeri Se-Kabupaten Bangka Tahun 2017, (3) Tidak ada hubungan positif antara metode mengajar guru terhadap hasil UN geografi siswa SMA Negeri Se-Kabupaten Bangka Tahun 2017.
\end{abstract}

\section{A B S T R A C T}

The location of the school affects students' learning outcomes. Schools located in villages and towns have different learning outcomes. Schools located in the city have better learning outcomes than schools located in the village. In addition, there are differences in the effectiveness of teaching teachers in the village and in the city thus affecting student learning outcomes. One measurement of learning outcomes conducted by the government of Indonesia is with the National Examination (UN). Geography is one of the specialization subjects that are included in the UN. Based on the assessment Puspendik, the results of UN Geography in Bangka District in 2017 fall into the category of being. This research is a descriptive quantitative research. The research sample is all SMAN in Bangka Regency. The tool used to collect data in the form of a questionnaire. (2) There is no positive correlation between school location to teaching method of geography teacher of SMA Negeri in all Bangka Regency in 2017, (2) There is no positive correlation between school location and geography of SMAN in all Bangka Regency in 2017, (3) There is no positive correlation between teacher teaching method toward the result of UN Geography of SMANin all Bangka Regency in 2017.

\footnotetext{
* Corresponding author.

E-mail addresses: meyziliaarvina@gmail.com,darsiharjo@upi.edu , mamatruhimat@upi.edu
} 



\section{Pendahuluan}

Lokasi sekolah mempengaruhi hasil belajar siswa. Hal ini juga dibuktikan oleh hasil penelitian Olusola, dkk (2014) yang melaporkan bahwa lokasi sekolah (di desa atau kota) dapat menjadi faktor yang menentukan hasil belajar siswa. Sekolah yang terletak di desa dan di kota memiliki hasil belajar yang berbeda. Sekolah yang terletak di kota memiliki hasil belajar yang lebih baik daripada sekolah yang terletak di desa (McCracken dan Barcinas, 1991; Musa, 2013; Owoeye dan Yara, 2011). Pendidikan di Indonesia baik di kota maupun di desa masih menghadapi berbagai persoalan. Anas, dkk (2014) dalam jurnalnya yang berjudul Desa dan Kota dalam Potret Pendidikan memaparkan bahwa kondisi pendidikan di kota besar yang biaya pendidikannya sudah gratis masih memiliki masalah yaitu masalah sulitnya biaya untuk membeli seragam dan juga buku-buku sekolah. Hal ini dikarenakan pihak sekolah tidak memberikan secara gratis sehingga akhirnya banyak anak-anak di kota yang putus sekolah dan akhirnya memilih untuk hidup di jalanan. Sedangkan kondisi pendidikan di desa tidak jauh berbeda dengan di kota persamaan masalahnya yaitu biaya dan juga masalah infrastruktur. Masyarakat desa yang miskin tidak akan bersekolah. Kondisi ini diperparah dengan infrastruktur yang tidak lengkap di desa, seperti tidak adanya SMA di suatu desa sehingga bila masyarakat desa ingin bersekolah maka mereka harus pergi sampai ke kota. Hal seperti ini membuat masyarakat miskin di desa makin sulit untuk mengakses pendidikan.

Selain itu, penelitian Olurotimi, dkk (2013) melaporkan bahwa ada perbedaan efektifitas mengajar guru di desa dan di kota sehingga mempengaruhi hasil belajar siswa. Masyarakat yang tinggal di desa dengan di kota juga tentu memiliki perilaku yang berbeda. Seperti yang disampaikan oleh Ruhimat (2016. hlm. 126), geograf lebih menekankan pada hubungan dan/atau interaksi antara penduduk dengan upaya pemanfaatan sumberdaya alam yang tersedia. Hubungan antara keduanya akan membentuk suatu pola perilaku tertentu sehingga dalam perkembangannya muncul pola perilaku penduduk desa dan kota. Perbedaan pola perilaku ini diduga membawa perbedaan pada metode mengajar guru di desa dan di kota. Perbedaan metode mengajar akan mempengaruhi hasil belajar siswa (Sudjana, 2014).

Salah satu pengukuran hasil belajar yang dilakukan pemerintah Indonesia adalah dengan Ujian Nasional (UN). Puspendik (Pusat Penilaian Pendidikan) memberikan klasifikasi rentang rata-rata nilai UN. Nilai rata-rata UN $>7,5$ termasuk dalam kategori baik sekali, rentang nilai $6,50 \mathrm{~s} / \mathrm{d}$ 7,50 termasuk dalam kategori baik, rentang nilai antara 5,50 s/d 6,50 termasuk dalam kategori sedang, rentang nilai 4,50 s/d 5,50 termasuk dalam kategori kurang, dan rentang $\leq 4,50$ termasuk dalam kategori kurang sekali.

Geografi merupakan salah satu mata pelajaran peminatan yang diikut sertakan dalam UN. Berdasarkan penilaian Puspendik, hasil UN Geografi di Kabupaten Bangka tahun 2017 tergolong dalam kategori sedang. Hasil belajar ini dipengaruhi oleh berbagai hal. Sudjana (2014) menjelaskan ada tiga unsur dalam kualitas pembelajaran yang mempengaruhi hasil belajar siswa yaitu kompetensi guru, karakteristik kelas, dan karakteristik sekolah. Slameto (2010) menambahkan faktor yang mempengaruhi belajar siswa terdiri dari faktor internal dan eksternal siswa. Faktor internal siswa terdiri dari intelegensi, minat, motif, perhatian, bakat, kematangan, dan kesiapan. Faktor eksternal yang mempengaruhi hasil belajar siswa yaitu faktor keluarga, faktor sekolah, dan faktor masyarakat.

Penelitian terdahulu banyak yang mengkaji mengenai hubungan antara metode mengajar guru terhadap hasil belajar siswa maupun hubungan antara lokasi sekolah (desa kota) terhadap hasil belajar siswa. Akan tetapi belum ada peneliti yang mengkaji hubungan antara lokasi sekolah terhadap metode mengajar guru dan hasil UN siswa. Oleh sebab itu peneliti tertarik untuk mengkaji mengenai permasalahan ini.

\section{Metode}

Berisi Penelitian ini merupakan penelitian kuantitatif deskritif. Populasi penelitian yaitu seluruh SMA Negeri di Provinsi Kepulauan Bangka Belitung. Sampel penelitian yaitu seluruh SMA Negeri di Kabupaten Bangka. Responden penelitian terdiri dari 214 siswa kelas XII IPS SMA Negeri se-Kabupaten Bangka dan 12 guru geografi SMA Negeri se-Kabupaten Bangka. Alat yang 
digunakan untuk mengumpulkan data berupa angket. Angket digunakan untuk mengetahui metode mengajar guru. Skala yang digunakan yaitu skala Likert. Mengacu pada skala Likert maka diberikan skor pada setiap alternatif yang dipilih responden. Adapun skornya sebagai berikut:

- $\quad$ Skor 5 untuk jawaban sangat sering

- $\quad$ Skor 4 untuk jawaban sering

- Skor 3 untuk jawaban kadang-kadang

- $\quad$ Skor 2 untuk jawaban jarang

- Skor 1 untuk jawaban tidak pernah

Untuk pertanyaan yang bersifat negatif, skor yang diberikan dibalik dengan skor yang ada pada jawaban di atas, yaitu:

- Skor 1 untuk jawaban sangat sering

- $\quad$ Skor 2 untuk jawaban sering

- Skor 3 untuk jawaban kadang-kadang

- Skor 4 untuk jawaban jarang

- Skor 5 untuk jawaban tidak pernah

Menentukan parameter metode mengajar guru dengan cara sebagai berikut:

a. Menentukan skor maksimal metode mengajar guru, dengan rumus:

Skor maksimal $=\Sigma$ item indikator $\mathrm{x}$ skor tertinggi tiap butir

$39 \times 5=195$

b. Menentukan skor minimal metode mengajar guru, dengan rumus:

Skor minimal $=\Sigma$ item indikator $\mathrm{x}$ skor terendah tiap butir

$39 \times 1=39$

c. Menghitung rentang skor, dengan rumus:

Rentang $=$ skor maksimal - skor minimal

$195-39=156$

d. Menghitung interval skor, dengan rumus:

Interval $=\frac{R}{B}$

$156 / 5$ = 31,2 dibulatkan menjadi 31 .

e. Menyusun tabel parameter dan frekuensi data metode mengajar guru yang disajikan seperti Tabel 1.

Tabel 1. Format Kriteria data Metode Mengajar Guru

\begin{tabular}{|c|c|c|c|}
\hline Interval & Kriteria & $\mathbf{F}$ & $\%$ \\
\hline 167 - 195 & Sangat tinggi & & \\
\hline $135-166$ & Tinggi & & \\
\hline $103-134$ & Sedang & & \\
\hline $71-102$ & Rendah & & \\
\hline $39-70$ & Sangat rendah & & \\
\hline \multicolumn{4}{|l|}{ Jumlah } \\
\hline \multicolumn{4}{|l|}{ Rata-Rata } \\
\hline Kriteria & & & \\
\hline
\end{tabular}

Keterangan $\%=\frac{f}{\Sigma f} \times 100$

Setelah kriteria metode mengajar guru diketahui, kriteria tersebut diasosiasikan terhadap kriteria hasil UN siswa. 


\section{Hasil dan pembahasan}

Hasil Berikut ini ditampilkan hasil penelitian ke dalam tabel kriteria metode mengajar guru.

Tabel 2. Kriteria Metode Mengajar Guru Geografi SMA N 1 Bakam

\begin{tabular}{|c|c|c|c|}
\hline Interval & Kriteria & $F$ & $\%$ \\
\hline $167-195$ & Sangat tinggi & 4 & 13,333 \\
\hline $135-166$ & Tinggi & 25 & 83,333 \\
\hline $103-134$ & Sedang & 1 & 3,333 \\
\hline $71-102$ & Rendah & 0 & 0,000 \\
\hline $39-70$ & Sangat rendah & 0 & 0,000 \\
\hline Jumlah & & 30 & 100 \\
\hline Rata-Rata & & \multicolumn{2}{|c|}{ Tinggi } \\
\hline Kriteria & & \multicolumn{3}{|c|}{} \\
\hline
\end{tabular}

Sumber: Data Primer Peneliti, 2018.

Tabel 2 menginformasikan bahwa metode mengajar guru geografi SMA N 1 Bakam sebesar 155,43. Angka tersebut menunjukkan bahwa metode mengajar guru geografi di SMA Negeri 1 Bakam tergolong tinggi.

Tabel 3. Kriteria Metode Mengajar Guru Geografi SMA N 1 Belinyu

\begin{tabular}{|c|c|c|c|}
\hline Interval & Kriteria & $F$ & $\%$ \\
\hline $167-195$ & Sangat tinggi & 6 & 20,00 \\
\hline $135-166$ & Tinggi & 22 & 73,33 \\
\hline $103-134$ & Sedang & 2 & 6,67 \\
\hline $71-102$ & Rendah & 0 & 0,00 \\
\hline $39-70$ & Sangat rendah & 0 & 0,00 \\
\hline Jumlah & & 30 & 100 \\
\hline Rata-Rata & & \multicolumn{2}{|c|}{ Tinggi } \\
\hline Kriteria & & \multicolumn{3}{|c|}{} \\
\hline
\end{tabular}

Sumber: Data Primer Peneliti, 2018.

Tabel 3 menginformasikan bahwa metode mengajar guru geografi SMA N 1 Belinyu sebesar 154,23. Angka tersebut menunjukkan bahwa metode mengajar guru geografi di SMA Negeri 1 Belinyu tergolong tinggi.

Tabel 4. Kriteria Metode Mengajar Guru Geografi SMA N 1 Mendo Barat

\begin{tabular}{|c|c|c|c|}
\hline \multicolumn{1}{|c|}{ Interval } & Kriteria & $F$ & $\%$ \\
\hline $167-195$ & Sangat tinggi & 0 & 0 \\
\hline $135-166$ & Tinggi & 15 & 93,75 \\
\hline $103-134$ & Sedang & 1 & 6,25 \\
\hline $71-102$ & Rendah & 0 & 0 \\
\hline $39-70$ & Sangat rendah & 0 & 0 \\
\hline Jumlah & & 16 & 100 \\
\hline Rata-Rata & & \multicolumn{2}{|c|}{ Tinggi } \\
\hline Kriteria & & \multicolumn{3}{|c|}{} \\
\hline
\end{tabular}

Sumber: Data Primer Peneliti, 2018.

Tabel 4 menginformasikan bahwa metode mengajar guru geografi SMA N 1 Mendo Barat sebesar 149,88. Angka tersebut menunjukkan bahwa metode mengajar guru geografi di SMA Negeri 1 Mendo Barat tergolong tinggi. 
Tabel 5. Kriteria Metode Mengajar Guru Geografi SMA N 2 Mendo Barat

\begin{tabular}{|c|c|c|c|}
\hline Interval & Kriteria & $F$ & $\%$ \\
\hline $167-195$ & Sangat tinggi & 1 & 8,33 \\
\hline $135-166$ & Tinggi & 9 & 75,00 \\
\hline $103-134$ & Sedang & 2 & 16,67 \\
\hline $71-102$ & Rendah & 0 & 0,00 \\
\hline $39-70$ & Sangat rendah & 0 & 0,00 \\
\hline Jumlah & & 12 & 100 \\
\hline Rata-Rata & & \multicolumn{2}{|c|}{148,27} \\
\hline Kriteria & & \multicolumn{2}{|c|}{ Tinggi } \\
\hline
\end{tabular}

Sumber: Data Primer Peneliti, 2018.

Tabel 5 menginformasikan bahwa metode mengajar guru geografi SMA N 2 Mendo Barat sebesar 148,27. Angka tersebut menunjukkan bahwa metode mengajar guru geografi di SMA Negeri 2 Mendo Barat tergolong tinggi.

Tabel 6. Kriteria Metode Mengajar Guru Geografi SMA N 1 Pemali

\begin{tabular}{|c|c|c|c|}
\hline Interval & Kriteria & $F$ & $\%$ \\
\hline $167-195$ & Sangat tinggi & 3 & 7,89 \\
\hline $135-166$ & Tinggi & 33 & 86,84 \\
\hline $103-134$ & Sedang & 2 & 5,26 \\
\hline $71-102$ & Rendah & 0 & 0 \\
\hline $39-70$ & Sangat rendah & 0 & 0 \\
\hline Jumlah & & 38 & 100 \\
\hline Rata-Rata & & \multicolumn{2}{|c|}{ Tinggi } \\
\hline Kriteria & & \multicolumn{3}{|c|}{} \\
\hline
\end{tabular}

Sumber: Data Primer Peneliti, 2018.

Tabel 6 menginformasikan bahwa metode mengajar guru geografi SMA N 1 Pemali sebesar 152,92 . Angka tersebut menunjukkan bahwa metode mengajar guru geografi di SMA Negeri 1 Pemali tergolong tinggi.

Tabel 7. Kriteria Metode Mengajar Guru Geografi SMA N 1 Puding Besar

\begin{tabular}{|c|c|c|c|}
\hline Interval & Kriteria & $F$ & $\%$ \\
\hline $167-195$ & Sangat tinggi & 4 & 26,67 \\
\hline $135-166$ & Tinggi & 11 & 73,33 \\
\hline $103-134$ & Sedang & 0 & 0 \\
\hline $71-102$ & Rendah & 0 & 0 \\
\hline $39-70$ & Sangat rendah & 0 & 0 \\
\hline Jumlah & & 15 & 100 \\
\hline Rata-Rata & & \multicolumn{2}{|c|}{159,33} \\
\hline Kriteria & & \multicolumn{2}{|c|}{ Tinggi } \\
\hline
\end{tabular}

Sumber: Data Primer Peneliti, 2018.

Tabel 7 menginformasikan bahwa metode mengajar guru geografi SMA N 1 Puding Besar sebesar 159,33. Angka tersebut menunjukkan bahwa metode mengajar guru geografi di SMA Negeri 1 Puding Besar tergolong tinggi.

Tabel 8. Kriteria Metode Mengajar Guru Geografi SMA N 1 Riau Silip

\begin{tabular}{|c|c|c|c|}
\hline Interval & Kriteria & $\mathrm{F}$ & $\%$ \\
\hline $167-195$ & Sangat tinggi & 0 & 0 \\
\hline $135-166$ & Tinggi & 8 & 50 \\
\hline
\end{tabular}




\begin{tabular}{|l|c|c|c|}
\hline $103-134$ & Sedang & 6 & 37,5 \\
\hline $71-102$ & Rendah & 2 & 12,5 \\
\hline $39-70$ & Sangat rendah & 0 & 0 \\
\hline Jumlah & & 16 & 100 \\
\hline Rata-Rata & \multicolumn{2}{|c|}{129,56} \\
\hline Kriteria & & \multicolumn{2}{|c|}{ Sedang } \\
\hline
\end{tabular}

Sumber: Data Primer Peneliti, 2018.

Tabel 8 menginformasikan bahwa metode mengajar guru geografi SMA N 1 Riau Silip sebesar 129,56 . Angka tersebut menunjukkan bahwa metode mengajar guru geografi di SMA Negeri 1 Riau Silip tergolong sedang.

Tabel 9. Kriteria Metode Mengajar Guru Geografi SMA N 1 Sungailiat

\begin{tabular}{|c|c|c|c|}
\hline Interval & Kriteria & $F$ & $\%$ \\
\hline $167-195$ & Sangat tinggi & 2 & 5,71 \\
\hline $135-166$ & Tinggi & 23 & 65,71 \\
\hline $103-134$ & Sedang & 10 & 28,57 \\
\hline $71-102$ & Rendah & 0 & 0,00 \\
\hline $39-70$ & Sangat rendah & 0 & 0,00 \\
\hline Jumlah & & 35 & 100 \\
\hline Rata-Rata & & \multicolumn{2}{|c|}{142,23} \\
\hline Kriteria & & \multicolumn{2}{|c|}{ Tinggi } \\
\hline
\end{tabular}

Sumber: Data Primer Peneliti, 2018.

Tabel 9 menginformasikan bahwa metode mengajar guru geografi SMA N 1 Sungailiat sebesar 142,23 . Angka tersebut menunjukkan bahwa metode mengajar guru geografi di SMA Negeri 1 Sungailiat tergolong tinggi.

Tabel 10. Kriteria Metode Mengajar Guru Geografi SMA N 1 Merawang

\begin{tabular}{|c|c|c|c|}
\hline \multicolumn{1}{|c|}{ Interval } & Kriteria & $F$ & $\%$ \\
\hline $167-195$ & Sangat tinggi & 0 & 0 \\
\hline $135-166$ & Tinggi & 13 & 56,52 \\
\hline $103-134$ & Sedang & 10 & 43,48 \\
\hline $71-102$ & Rendah & 0 & 0 \\
\hline $39-70$ & Sangat rendah & 0 & 0 \\
\hline Jumlah & & 23 & 100 \\
\hline Rata-Rata & & \multicolumn{2}{|c|}{ Tinggi } \\
\hline Kriteria & & \multicolumn{2}{|c|}{} \\
\hline
\end{tabular}

Sumber: Data Primer Peneliti, 2018.

Tabel 10 menginformasikan bahwa metode mengajar guru geografi SMA N 1 Merawang sebesar 134,91. Angka tersebut menunjukkan bahwa metode mengajar guru geografi di SMA Negeri 1 Merawang tergolong tinggi.

Tabel 11. Hubungan Antara Lokasi Sekolah Terhadap Metode Mengajar Guru Geografi SMA Negeri Kabupaten Bangka Tahun 2017

\begin{tabular}{|l|c|c|c|}
\hline \multicolumn{1}{|c|}{ Sekolah } & Lokasi & $\begin{array}{c}\text { Hasil Metode Mengajar Guru } \\
\text { Berdasarkan Perhitungan } \\
\text { Statistika }\end{array}$ & $\begin{array}{c}\text { Kriteria Metode } \\
\text { Mengajar Guru }\end{array}$ \\
\hline SMA N 1 Bakem & Desa & 155,43 & Tinggi \\
\hline SMA N 1 Belinyu & Kota & 154,23 & Tinggi \\
\hline SMA N 1 Mendo Barat & Desa & 149,88 & Tinggi \\
\hline SMA N 2 Mendo Barat & Desa & 148,27 & Tinggi \\
\hline
\end{tabular}




\begin{tabular}{|l|c|c|c|}
\hline SMA N 1 Pemali & Desa & 152,92 & Tinggi \\
\hline SMA N 1 Puding Besar & Desa & 159,33 & Tinggi \\
\hline SMA N 2 Puding Besar & Desa & Sekolah Baru & Sekolah Baru \\
\hline SMA N 1 Riau Silip & Desa & 129,56 & Sedang \\
\hline SMA N 1 Sungailiat & Kota & 142,23 & Tinggi \\
\hline SMA N 1 Merawang & Desa & 134,91 & Tinggi \\
\hline
\end{tabular}

Sumber: Data Primer Peneliti, 2018.

Tabel 11 menginformasikan bahwa tidak ada hubungan antara lokasi sekolah terhadap metode mengajar guru. Metode mengajar guru geografi di kota dan di desa sama-sama tergolong tinggi.

Tabel 12. Hubungan Antara Lokasi Sekolah Terhadap Hasil UN Matapelajaran Geografi SMA Negeri Kabupaten Bangka Tahun 2017

\begin{tabular}{|l|c|c|c|}
\hline \multicolumn{1}{|c|}{ Sekolah } & Lokasi & Hasil UN & $\begin{array}{c}\text { Kriteria Hasil UN } \\
\text { Berdasarkan } \\
\text { Penilaian Puspendik }\end{array}$ \\
\hline SMA N 1 Bakem & Desa & 49,33 & Kurang \\
\hline SMA N 1 Belinyu & Kota & 66,67 & Baik \\
\hline SMA N 1 Mendo Barat & Desa & 55,88 & Sedang \\
\hline SMA N 2 Mendo Barat & Desa & 58,67 & Sedang \\
\hline SMA N 1 Pemali & Desa & 52,18 & Kurang \\
\hline SMA N 1 Puding Besar & Desa & 49,27 & Kurang \\
\hline SMA N 2 Puding Besar & Desa & Sekolah Baru & Sekolah Baru \\
\hline SMA N 1 Riau Silip & Desa & 55,50 & Sedang \\
\hline SMA N 1 Sungailiat & Kota & 68,00 & Baik \\
\hline SMA N 1 Merawang & Desa & 44,80 & Kurang Sekali \\
\hline
\end{tabular}

Sumber: Data UN dari Kemendikbud, 2017; Data lokasi sekolah, 2018.

Tabel 12 menunjukkan hasil UN siswa pada sekolah yang terletak di kota tergolong lebih tinggi daripada sekolah yang terletak di desa. Hal ini menunjukkan bahwa ada hubungan antara lokasi sekolah terhadap hasil UN geografi siswa tahun 2017.

Tabel 13. Hubungan Antara Lokasi Sekolah Terhadap Metode Mengajar Guru dan Hasil UN Matapelajaran Geografi SMA Negeri Kabupaten Bangka Tahun 2017

\begin{tabular}{|l|c|c|c|}
\hline \multicolumn{1}{|c|}{ Sekolah } & $\begin{array}{c}\text { Lokasi } \\
\text { Sekolah }\end{array}$ & $\begin{array}{c}\text { Kriteria Metode Mengajar } \\
\text { Guru Berdasarkan } \\
\text { Perhitungan Statistika }\end{array}$ & $\begin{array}{c}\text { Kriteria Hasil UN } \\
\text { Berdasarkan } \\
\text { Penilaian Puspendik }\end{array}$ \\
\hline SMA N 1 Bakem & Desa & Tinggi & Kurang \\
\hline SMA N 1 Belinyu & Kota & Tinggi & Baik \\
\hline SMA N 1 Mendo Barat & Desa & Tinggi & Sedang \\
\hline SMA N 2 Mendo Barat & Desa & Tinggi & Kurang \\
\hline SMA N 1 Pemali & Desa & Tinggi & Kurang \\
\hline SMA N 1 Puding Besar & Desa & Tinggi & Sekolah Baru \\
\hline SMA N 2 Puding Besar & Desa & Sekolah Baru & Sedang \\
\hline SMA N 1 Riau Silip & Desa & Sedang & Kaik \\
\hline SMA N 1 Sungailiat & Kota & Tinggi & Tinggi \\
\hline SMA N 1 Merawang & Desa & & \\
\hline
\end{tabular}

Sumber: Diolah oleh Peneliti, 2018.

Tabel 13 menunjukkan bahwa metode mengajar guru yang memiliki kriteria tinggi tidak berbanding dengan kriteria hasil UN siswa. Artinya, kriteria metode mengajar guru tinggi tetapi hasil belajar siswa masih sedang atau kurang. Sehingga dapat disimpulkan bahwa tidak ada hubungan antara metode mengajar guru terhadap hasil UN geografi tahun 2017 di SMA Negeri 
Se- Kabupaten Bangka. Hasil penelitian juga menunjukkan bahwa sekolah yang terletak di kota memiliki hasil UN yang lebih baik daripada sekolah yang terletak di desa. Akan tetapi, tidak ada hubungan yang positif antara lokasi sekolah dengan metode mengajar guru. Metode mengajar guru di desa dan di kota tergolong tinggi.

\section{Simpulan dan saran}

Hasil penelitian menyimpulkan bahwa;

- Ada hubungan positif antara lokasi sekolah terhadap hasil UN geografi siswa SMA Negeri Se-Kabupaten Bangka Tahun 2017.

- Tidak ada hubungan positif antara lokasi sekolah terhadap metode mengajar guru geografi SMA Negeri Se-Kabupaten Bangka Tahun 2017.

- Tidak ada hubungan positif antara metode mengajar guru terhadap hasil UN geografi siswa SMA Negeri Se-Kabupaten Bangka Tahun 2017.

Hasil penelitian menyarankan untuk pihak sekolah agar lebih meningkatkan hasil UN matapelajaran geografi di seluruh SMA Negeri Kabupaten Bangka. Hal ini dikarenakan hasil UN matapeajaran geografi di Kabupaten Bangka masih tergolong sedang (berdasarkan penilaian Puspendik).

\section{Daftar Rujukan}

Anas, Azwar Yusran, dkk. 2014. Desa dan Kota dalam Potret Pendidikan. PROSIDING KS: RISET \& PKM. 2(3): 301-444, ISSN: 2442-4480.

McCracken dan Barcinas. 1991. Differences Between Rural and Urban Schools, Student Characteristics, and Student Aspirations in Ohio. Journal of Research in Rural Education, Winter, 7(2): 29-40.

Musa, Alice, K.J. 2013. Gender, Geography Locations, and achievement goals and academic performance of secondary school students from Borno State, Nigeria. Research in Education, Number 90. http://dx.doi.org/10.7227/RIE.90.1.2.

Olusola, dkk. (2014). Impact of School Location on Academic Achievement of Science Students in Senior Secondary School Certificate. International Journal of Scientific and Research Publications. 4(9), ISSN 2250-3153.

Olurotimi, Ogunlade Joseph, dkk. 2013. Teacher Distribution Pattern as Determinant of Effective Teaching and Learning in Nigeria Secondary Schools. International Journal of Science and Research (IJSR) ISSN (Online): 2319-7064 Index Copernicus Value (2013): 6.14. Impact Factor (2013): 4.43.

Owoeye, Joseph Sunday dan Yara, Philias Olatunde. 2011. School Location and Achievement of Secondary School in Ekiti State, Nigeria. Jurnal Asian Social Science. 7(5). www.ccsenet.org/ass

Ruhimat, Mamat. 2016. Geografi Penduduk. Yogyakarta: Ombak.

Slameto. 2015. Belajar dan Faktor-Faktor yang Mempengaruhinya. Edisi Revisi. Jakarta: Rineka Cipta.

Sudjana, Nana. 2014. Dasar-Dasar Proses Belajar Mengajar. Bandung: Sinar Baru Algensindo 